\title{
Rancang Bangun Aplikasi Pemesanan Air Bersih Berbasis Android Dengan Menggunakan Model Prototype
}

\author{
Mariano Do Rosario Pinto ${ }^{1}$, Wahyu Widodo ${ }^{2}$, Andy Rachman ${ }^{2}$ \\ 1,2,3 Jurusan Teknik Informatika - Institut Teknologi Adhi Tama Surabaya \\ Email: ${ }^{1}$ marianopinto96@gmail.com, ${ }^{2}$ wahyu.e20.its@gmail.com, ${ }^{3}$ andy.rach1910@itats.ac.id
}

\begin{abstract}
Water is the main source of living creatures particularly for humans. It becomes the basic human need or primary need for daily activities such as drinking, cooking, taking a bath, and even operating industry. Therefore, water has both economic and social functions. This research designed digital-based application for ordering clean water in South Central Timor Regency, East Nusa Tenggara Province. It aimed at designing android-based application system using prototype model. This application was developed by programming languages of Java, $X M L$, SQLite, PHP, Javascript, and MySQL database. Android studio was used to develop software for android application. There are two kinds of users namely administrator and customer in this application. Every feature of each user successfully showed, ordered, added, and updated the data of product. Trial on users by alpha and beta tests reported that this application system was able to operate accurately parts of menu and obtained $93.20 \%$.
\end{abstract}

Keywords: prototype model, java, xml, SQLite, PHP, Javascript, MySql, Android Studio

\begin{abstract}
Abstrak. Air sebagai sumber kehidupan makhluk hidup terutama manusia yang berkembang dengan berbagai macam kebutuhan dasar manusia (basic human need). Air menjadi kebutuhan primer yang diperlukan untuk kebutuhan sehari-hari seperti minum, masak, mandi sampai kebutuhan pengolahan industri, sehingga fungsi air tidak hanya terbatas untuk menjalankan fungsi ekonomi saja, namun juga sebagai fungsi sosial. Penelitian ini menawarkan sebuah aplikasi pemesanan air bersih agar dapat membatu proses pemesanan air bersih di Kabupaten Timor Tengah Selatan (TTS) Provinsi Nusa Tenggara Timur (NTT) menggunakan aplikasi digital. Tujuan penelitian ini adalah merancang sistem aplikasi pemesanan air bersih berbasih andorid. Metode pengembangan sistem yang digunakan dalam pembuatan aplikasi ini menggunakan model prototype. Aplikasi pemesana ini dikembang berdasarkan sistem aplikasi android. Aplikasi pemesanan ini dibangun menggunakan bahasa pemrograman Java, XML, SQLite, PHP, Javascript dan database MySql. Software pengembang aplikasi android menggunakan android studio. Penelitian ini menghasilkan 2 user berbeda yaitu admin dan customer. Setiap fitur pada masing-masing user berhasil untuk menampilkan, memesan produk, menambahkan produk, serta update data produk. Dari Hasil pengujian yang diperoleh dengan menggunakan pengujian alpha dan pengujian beta, sistem aplikasi berhasil mengoperasikan bagian-bagian mеnu serta memperoleh nilai persentase $93.20 \%$ berupa hasil pengujian yang dicoba pada pengguna.
\end{abstract}

Kata Kunci: model prototype, java, xml, SQLite, PHP, javascript, MySql, android studio

\section{Latar Belakang}

Air merupakan salah satu unsur yang peling penting dimuka bumi ini. Manusia dalam kehidupannya sangat memerlukan dan membutuhkan air. Hal ini dapat dilihat bahwa tubuh manusia lebih dari $75 \%$ terdiri dari air dan selebihnya adalah berupa bahan padat. Sifat air yang berupa cairan yang tidak berwarna, tidak berbau dan tidak berasa menjadikan air sebagai salah satu zat yang diperlukan oleh manusia (Ritonga, 2011). Indonesia merupakan salah satu negara yang memiliki jumlah hutan yang sangat besar. Hutan di Indonesia ini menjadi sangat penting karena menjadi cadangan sumber energi dan pengendali cuaca serta pengatur siklus air (Sutoyo, 2010). Winda Rahmawati dkk, tahun 2018 pada penelitiannya menjelaskan tentang hutan sebagai sumber kehidupan yang perlu dijaga untuk kesejahteraan masyarakat dimana pada penelitiannya, peneliti menjelaskan tentang keberadaan Undang-Undang no. 41 tahun 199 yang mengatur perlindungan hutan yang ada di Indonesia. Untuk melindungi hutan yang ada di Indonesia, Pemerintah mengeluarkan undang-undang no. 41 tahun 1999 yang mengatur perlindungan hutan. Dengan menjaga hutan, maka akan dapat mencegah terjadinya banjir, pengendalian erosi, dan memelihara kesuburan tanah (Rahmawati et al., 2018). Sejalan dengan undang-undang no. 41 tahun 1999, Novita M.D. dan Marsono B.D., pada penelitiannya tahun 2019 
menjelaskan tentang Peraturan Menteri Pekerjaan Umum Nomor 27 tahun 2016 dimana untuk menyelenggarakan sistem persediaan air minum bagi masyarakat yang sehat, bersih dan produktif diperlukan Sistem Pengelolaan Air Minum Regional berupa BUMN ataupun BUMD (Novita \& Marsono, 2019).

Kabupaten Timor Tengah Selatan merupakan salah satu Kabupaten yang berada disalah satu Provinsi Nusa Tenggara Timur (NTT) yang terletak pada longtitude 124.419824 dan latitude -9.776282. Kabupaten Timor Tengah Selatan (TTS) merupakan wilayah yang memiliki curah hujan dibawah normal dimana musim kemaru bisa terjadi antara delapan sampai sembilan bulan bahkan Kabupaten TTS sering mengalami kondisi kekeringan sepanjang tahun. Dengan kondisi lingkungan yang berbukit-bukit, PDAM Kabupaten TTS masih belum mampu memberikan pelayanan distribusi air bersih kepada seluruh masyarakat (Jocom et al., 2016). Makauri A.M dkk, tahun 2016 yang berjudul "Perencanaan Teknis Jaringan Air Bersih Di Desa Nunusunu Kecamatan Kualin Kabupaten Timor Tengah Selatan" memaparkan tentang kondisi air bersih di Kabupaten Timor Tengah Selatan khususnya di Desa Nunusunu Kecamatan Kualin. Peneliti menggunakan metode volumetrik untuk mengukur debit air dan didapatkan kebutuhan air perdetik adalah sebesar 0,991 liter pada puncak kemarau dibulan November. Peneliti memprediksi penduduk di Desa Nunususu tahun 2034 adalah sebesar 1337 orang sehingga kebutuhan yang diperlukan adalah 0,712 liter/detik. Sehingga disarankan agar PDAM, Dinas Pekerjaan Umum dan Dinas Kesehatan mampu membantu penyediaan air bersih di Desa Nunususu (Maukari et al., 2016).

Perangkat lunak merupakan bagian dari sebuah komputer, dimana sebuah komputer atau sistem komputer terdiri dari dua bagian utama yaitu perangkat keras dan perangkat lunak. Perangkat lunak komputer atau dikenal dengan sebutan aplikasi merupakan suatu perangkat lunak yang dibuat atau diciptakan untuk menyelesaikan masalah-masalah tertentu (Sulistyowati et al., 2017). Untuk membuat sebuah aplikasi diperlukan model pengembangan perangkat lunak dimana saat ini terdapat beragam model pengembangan perangkat lunak, mulai dari waterfall, rapid application development, v-model, prototype, incremental, extremen programming, kanban, scrum, dan dynamic system development method (Rachman, Prasetyo, et al., 2019). Gautham B.G.V, dkk, tahun 2015 pada penelitiannya yang berjudul "Provisions Ordering Smartphone Application Using Android" memaparkan tentang pengembangan aplikasi pemesanan berbasiskan smartphone android. Pada pengembangan aplikasi ini peneliti menggunakan database dalam menyimpan data transaksinya menggunakan database SQLite (Gautham et al., 2015).

Dari latar belakang permasalahan yang diteliti adalah bagaimana mengembangkan sistem aplikasi pemesanan air bersih berbasis android bagi kabupaten Timor Tengah Selatan Provinsi Nusa Tenggara Timur.

\section{Tinjauan Pustaka}

\subsection{Teknologi Informasi dan Komunikasi}

Teknologi Informasi dan Komunikasi di Indonesia saat ini telah berkembang dengan sangat pesatnya. Teknologi Informasi dan Komunikasi disingkat dengan TIK. Dengan adanya teknologi pekerjaan manusia menjadi lebih terbantukan serta dengan adanya teknologi tersedianya berbagai macam hiburan bagi masyarakat Indonesia. Dua aspek yang ada dalam TIK adalah aspek teknologi informasi dan aspek teknologi komunikasi. Aspek teknologi informasi berhubungan dengan proses, manipulasi, penggunaan alat bantu serta pengelolaan informasi, sedangkan aspek teknologi komunikasi merupakan aspek dimana proses komunikasi dapat berjalan dengan baik dan benar antara pengirim dan penerima informasi (Huda, 2020). Edy Prayitno, dkk, ditahun 2018, pada penelitiannya memaparkan tentang pemanfaatan Teknologi Informasi dan Komunikasi (TIK) dalam proses pembelajaran. Pada penelitiannya, para peneliti melakukan pelatihan terhadap Guru, dan Siswa. Pelatihan terhadap Guru berfokus pada pemanfaatan Microsoft Office untuk pembuatan Rencana Pelaksanaan Pembelajaran (RPP) dan untuk siswa pelatihan yang dilaksanakan adalah pencarian materi dan internet sehat serta pengetahuan tentang undang-undang ITE. Peneliti juga mengembangkan aplikasi perpustakaan untuk membantu sekolah mengelola data perpusatakaan sekolah. Dari hasil penelitian didapatkan data bahwa penelitian yang dilaksanakan dalam hal peningkatan kemampuan guru dan siswa di dua sekolah adalah berhasil meningkatakan kemampuan guru dan siswa antara 2,1\% sampai 4\% dari kondisi awal (Prayitno et al., 2018).

Risma Nurul Auliya, dkk, tahun 2020, pada penelitiannya memanfaatkan Microsoft Mathematics 4.0 sebagai media pembantu pembelajaran di SMA dan SMK Adhi Luhur 2 Jakarta. Peneliti mengadakan pelatihan pembelajaran matematika dengan menggunakan teknologi Microsoft Mathematics. Aplikasi ini telah dapat membantu proses pembelajara matematika di SMA dan SMK Adhi Luhur 2 Jakarta (Auliya et al., 2020). Hendra Rohman dan Selin Sheralinda, tahun 2020, pada penelitiannya mengembangkan sistem 
informasi rawat jalan dan pelayanan persalinan di Klinik Citra Madina. Aplikasi yang dikembangkan oleh peneliti adalah aplikasi berbasiskan web. Aplikasi yang dikembangkan mempunyai fitur pengeleloaan data pemeriksaan pasien umu, dan ibu hamil, serta mampu memberikan laporan penyakit, laporan obat, dan pembayaran (Rohman \& Sheralinda, 2020). Ditha Prasanti dan Sri Seti Indriani, tahun 2018, pada penelitiannya mengembangkan teknologi informasi dan komunikasi dalam bentuk sistem E-Health Alodokter.com. Aplikasi ini dapat diakses melalui web, media sosial maupun sistem operasi android pada googleplay. Aplikasi telah diuji coba dimasyarakat dan mendapatkan respon yang baik. Aplikasi ini memberikan informasi tentang berbagai penyakit, obat, dan bahkan konsultasi dengan dokter (Prasanti \& Indriani, 2018). Alhadi Saputra dan Yudho Giri Sucahyo, tahun 2018, pada penelitiannya membahas tentang rancangan tata kelola organisasi yang ada di dinas komunikasi dan informatika kabupaten bekasi. Tata kelola tersebut diuji dengan menggunakan ISO/IEC 27001:2013 untuk dapat mengetahui sistem manajemen keamanannya. Dari penelitin ini didapatkan bahwa sistem manajemen keamanan informasi yang ada di pemerintahan kabupaten Bekasi masih perlu ditingkatkan kembali setelah diuji dengan menggunakan ISO/IEC 27001:2013 (Saputra \& Sucahyo, 2018). Pemanfaatan teknologi informasi dan komunikasi telah digunakan disegala bidang kehidupan masyarakat di Indonesia, baik dari sisi pendidikan, kesehatan, ataupun pemerintahan.

\subsection{Rekayasa Perangkat Lunak dan Implementasinya}

Rekayasa perangkat lunak merupakan bidang ilmu yang memberikan pengetahuan tentang pengembangan sebuah aplikasi dengan cara yang baik dan benar sehingga sebuah aplikasi berfungsi dengan tujuan diciptakannya dan menghasilkan informasi yang bermanfaat dan berguna bagi penggunanya. Informasi sendiri merupakan kumpulan data yang telah diolah sedemikian rupa sehingga berarti bagi penerima informasi dan bermanfaat dalam pengambilan sebuah keputusan (Anisya \& Allazi, 2017). Harison dan Sisri Maida Ayu, tahun 2017, pada penelitiannya mengembangkan aplikasi pengolahan data produk masuk dan keluar dengan menggunakan PHP dan database MySQL pada perusahaan Suzuya Rocky di kota Padang. Perusahaan ini menjalankan dua produk unggulan yaitu produk fashion dan produk swalayan. Aplikasi telah diimplementasikan ke perusahaan Suzuya Rocky dan digunakan pihak SPG, Kasir, Suplier dan brand (Harison \& Ayu, 2017). Untuk mengembangkan sebuah aplikasi, para pengembang menggunakan model proses pengembangan perangkat lunak, beberapa diantaranya adalah waterfall, incremental, prototype, $v$ shaped, bahkan model cepat (agile) (Rachman, Fatimah, et al., 2019).

Afif Bachtiar, dkk, tahun 2019, pada penelitiannya mengembangkan sebuah game berjudul "Vox Rescue" yang dikembangkan dengan game engine Unity. Pengembangan game "Vox Rescue" menggunakan model pengembangan perangkat lunak model spiral. Aplikasi diuji oleh 53 pengguna dan mendapatkan hasil kepuasan pengguna sebesar $82,6 \%$ dan dari sisi fungsionalitasnya mendapatkan nilai sebesar 82,3\% (Bahtiar et al., 2019). N F Rozi, dkk, tahun 2019, pada penelitiannya mengembangkan aplikasi rental mobil berbasiskan web yang diberi nama LIDI. Aplikasi rental mobil ini dikembangkan dengan menggunakan framework MVC. Aplikasi ini dikembangkan khusus rental bagi pengusaha rental mobill yang ada didaerah Sidoarjo, Jawa Timur. Aplikasi telah diuji oleh pengguna dan pemilik rental mobil dengan nilai rata-rata baik sehingga aplikasi LIDI layak untuk digunakan bagi pemilik rental mobil (Rozi et al., 2019). Edryanto, dkk, tahun 2020, pada penelitiannya mengembangkan aplikasi berbasiskan augmented reality tentang pengenalan landmark asia tenggara. Aplikasi ini dikembangkan bagi siswa Sekolah Dasar Negeri 139/IV Jambi. Aplikasi ini ditujukan bagi sistem operasi android. Aplikasi digunakan sebai media pembantu dalam proses belajar materi IPS. Aplikasi dibangun dengan menggunakan model Spiral (Edryanto et al., 2020).

Usman Ependi, tahun 2018, pada penelitiannya mengimpementasikan model scrum dalam pengembangan aplikasi seleksi masuk mahasiswa politeknik pariwisata palembang. Scrum merupakan salah satu model pengembangan aplikasi secara cepat (agile). Selain Scrum masih terdapat beberapa model cepat lainnya, yaitu eXtreme Programming (XP), crystal, dynamic system development method (DSDM), feature driven development, dan lainnya. Aplikasi yang dibangun peneliti telah sesuai dengan kebutuhan pengguna, yaitu peserta dan panitia (Ependi, 2018). Mohammad Arif Muttaqin, dkk, tahun 2020, pada penelitiannya mengembangkan aplikasi stok audit bagi perusahaan PT. Media Sarana Data dengan menggunakan model view presenter. Aplikasi yang dikembangkan ini berbasis android. Peneliti menggunakan pengujian berjenis black box testing. Aplikasi telah digunakan oleh perusahaan dan berhasil sesuai dengan tujuan pembuatan aplikasi (Muttaqin et al., 2020). Wina Witanti, dkk, tahun 2020, pada penelitiannya mengembangkan sistem 
informasi perpustakaan digital dengan menggunakan model waterfall. Aplikasi yang dikembangkan diimplementasikan pada Universitas Jenderal Achmad Yani, Jawa Barat. Peneliti menggunakan framework CodeIgnitier dengan menggunakan model MVC (Model, View, Controller). Dengan aplikasi ini, Universitas Jenderal Achmad Yani memiliki perpustakaan online yang dapat menangani peminjaman, pengembalian, Data E-Book, dan fungsi-fungsi lainnya (Witanti et al., 2020). Dari penelitian yang ada, dalam pengembangan aplikasi, para peneliti menggunakan beberapa cara, antara lain menggunakan model, teknologi, framework, pendekatan dan melakukan kombinasi dengan satu atau beberapa algoritma, mulai dari First In First Out (FIFO), Greedy String Tilling, Dijkstra, dan lain-lain. Dengan penggunaan model, framework, pendekatan, ataupun algoritma ditujukan agar aplikasi yang dikembangkan memiliki kehandalan, efektifitas, kecepatan akses yang sesuai dengan tujuan peneliti.

\section{Metode}

Dalam mengembangkan aplikasi peneliti menggunakan model prototype. Model ini memiliki lima langkah utama, yaitu Communication (komunikasi), Quick Plan (Perencanaan Cepat), Modeling Quick Design (Pemodelan Desain Secara Cepat), Construction of Prototype (Membangun Prototipe), dan Development Delivery \& Feedback. Tahap pertama,yaitu communication (komunikasi). Peneliti melakukan survey ke daerah Timor Tengah Selatan. Disana kami bertemu dengan penanggungjawab daerah dan menayakan tentang informasi air bersih, dari kegiatan ini didapatkan bahwa untuk mendapatkan air bersih sangatlah sulit dan jikapun ada harganya mahal. Selain kondisi dan harga, peneliti juga menanyakan tentang proses pemesanan air dan pengirimannya. Dari kegiatan ini peneliti segera melakukan perencanan pengembangan aplikasi. Dari kegiatan kedua Quick Plan (perencanaan) peneliti menentukan, bahwa aplikasi harus dapat diakses secara cepat dalam kondisi apapun, oleh karena itu kami menentukan aplikasi berbasiskan android. Aplikasi harus dibuat sesederhana mungkin dan mudah digunakan sesuai dengan kondisi masyarakat di Timor Tengah Selatan. Pengguna harus dapat memesan air dan melihat status air yang ada.

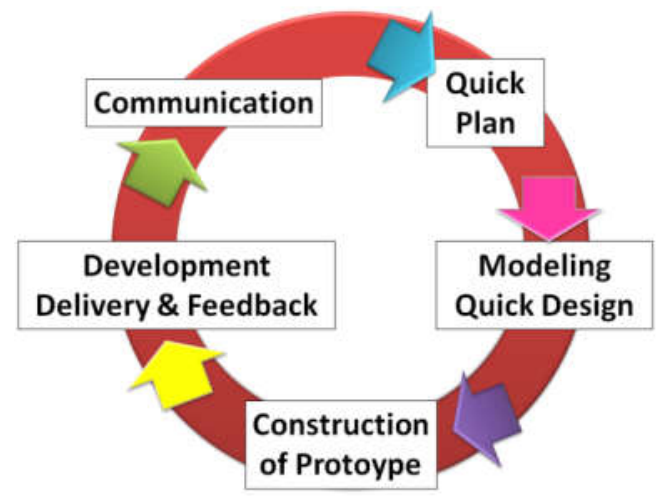

\section{Gambar 1. Model Prototype sebagai Model Pengembangan Aplikasi Pemesanan Air Bersih.}

Pada tahap ketiga, peneliti melakukan proses pemodelan desain aplikasi pemesanan air bersih. Disini pada gambar 2 didapatkan bahwa pelanggan (customer) dapat melakukan empat kegiatan utama, yaitu login, register, meilhat data produk yang dijual (paket yang ada), dan memasukkan data pemesanan air bersih. Pelanggan dapat mengakses paket-paket yang ada pada web atau aplikasi android yang telah diinstall pengguna. Untuk melakukan proses pemesanan air bersih maka pelanggan harus melakukan proses login terlebih dahulu, jika pelanggan belum memiliki keanggotaan, maka pelanggan dapat melakukan proses register terlebih dahulu. Setelah proses register dilaksanakan maka proses selanjutnya adalah pelanggan melakukan login. Setelah proses login pelanggan dapat melakukan proses pemesanan air bersih yang ada. Dari sisi pemilik, dapat melakukan empat kegiatan utama, yaitu login, input data produk paket pemesanan air bersih, melihat data pemesanan air bersih, serta mendapatkan laporan penjualan dan pemesanan air bersih. 


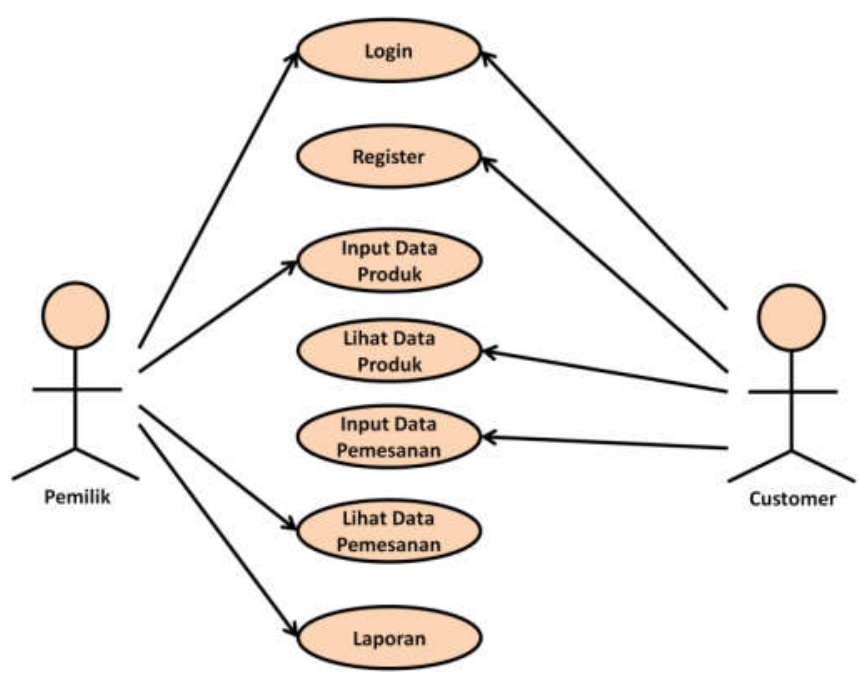

\section{Gambar 2. Use Case Diagram Aplikasi Pemesanan Air Bersih}

Pada langkah keempat adalah proses construction of prototype (desain prototype). Peneliti melakukan desain prototipe aplikasi untuk menu register, login, data produk, input data pemesanan, detail pemesanan, dan laporan pelanggan seperti terlihat pada gambar 3 .
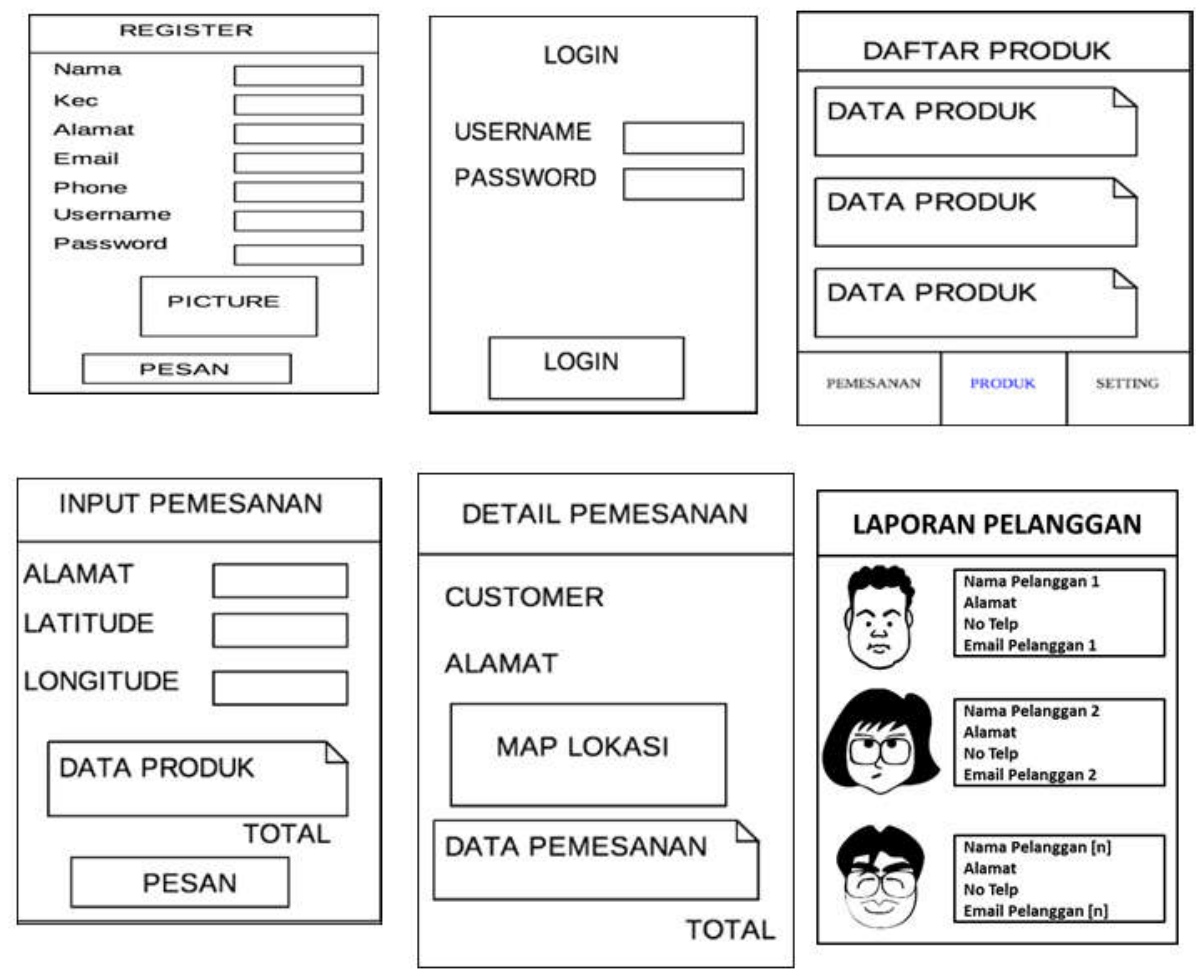

Gambar 3. Desain Prototype Aplikasi Pemesanan Air Bersih

Pada langkah terakhir, peneliti melakukan pengembangan, pengiriman ke pelanggan dan pemilik, serta mendapatkan feedback dari uji dan pengembangan aplikasi pemesanan aplikasi air bersih. Pada tahap pengembangan aplikasi, peneliti menggunakan android studio dan dbms SQLLite sera emulator Bluestack. Pada tahap delivery, peneliti langsung menguji kepihak yang berkepentingan, dalam hal ini adalah pemilik ata penjual air bersih dan beberapa warga disekitar penjual air bersih. Pengujian menggunakan alpha testing dan 
beta testing. Setelah aplikasi dicoba, peneliti melakukan proses tanya jawab seputar kegunaan aplikasi. Pemilik penyedia air bersih merasa terbantukan dengan adanya aplikasi penjualan air bersih yang dikembangkan peneliti, begitu juga pada pelanggan, merasa sangat tertolong dengan adanya aplikasi pemesanan air bersih, karena para pelanggan dapat mengetahui harga beli air bersih dan tidak perlu susah payah mencari penjual air saat air bersih sudah dalam kondisi menipis, pelanggan tinggal mengakses aplikasi, input data pembelian, dan air sudah dikirim oleh penjual.

\section{Kesimpulan}

Pada penelitian ini, kesimpulan yang dapat diambil setelah aplikasi dikembangan dan diimplementasikan kemasyarakat Timor Tengah Selatan antara lain:

1. Peneliti telah berhasil mengembangkan Aplikasi Pemesanan Air Bersih dengan menggunakan model pengembangan perangkat lunak Prototype.

2. Aplikasi telah diuji oleh penyedia air bersih dan oleh pelanggan air bersih dan mendapatkan penilaian sebesar 93,20\% yang berarti aplikasi sangat berguna bagi pemilik dan pengguna aplikasi.

3. Penyedian air bersih merasa sangat terbantukan dengan adanya Aplikasi Pemesanan Air Bersih.

4. Pelanggan air bersih jugsa sangat tertolong dengan adanya aplikasi pemesanan air bersih karena adanyara transparansi penjualan air bersih serta air dapat dikirimkan ke pelanggan sehingga pelanggan tidak perlu harus mencari dan membawa sendiri air bersih yang diperlukan.

\section{Referensi}

Anisya, \& Allazi, E. (2017). Rekayasa Perangkat Lunak Penjadwalan dan Pemesanan Iklan Radio (Studi Kasus: Radio Classy FM). Jurnal CoreIT, 3(2), 82-88.

Auliya, R. N., Pinahayu, E. A. R., \& Adnyani, L. P. W. (2020). Pemanfaatan Microsoft Mathematics 4.0 dalam Pengembangan Pembelajaran Matematika di SMA/SMK. E-DIMAS: Jurnal Pengabdian Kepada Masyarakat, 11(1), 107-144.

Bahtiar, A., Muhima, R. R., \& Rachman, A. (2019). Penerapan Model Spiral Pada Rancang Bangun Game Platformer. SEMINAR NASIONAL SAINS DAN TEKNOLOGI TERAPAN VII (SNTEKPAN VII), 601-606.

Edryanto, Irawan, \& Effiyaldi. (2020). PERANCANGAN APLIKASI AUGMENTED REALITY PENGENALAN LANDMARK ASIA TENGGARA BERBASIS ANDROID PADA SDN 139/IV JAMBI. Jurnal Ilmiah Mahasiswa Teknik Informatika, 2(1), 31-42.

Ependi, U. (2018). Implementasi Model Scrum pada Sistem Informasi Seleksi Masuk Mahasiswa Politeknik Pariwisata Palembang. Jurnal Informatika:Jurnal Pengembangan IT (JPIT), 3(1), 49-55.

Gautham, B. G. V., Arun, A., Raj, M. H., \& Rajeswari, D. (2015). Provisions Ordering Smartphone Application Using Android. International Journal of Advance Research in Computer Science and Management Studies, 3(3), 81-87.

Harison, A., \& Ayu, S. M. (2017). REKAYASA PERANGKAT LUNAK PENGOLAHAN DATA PRODUK MASUK DAN KELUAR MENGGUNAKAN PHP DAN MySQL (Studi Kasus: Suzuya Rocky Plaza Padang). Jurnal TEKNOIF, 5(1), 23-29. https://doi.org/10.21063/JTIF.2017.V5.1.23-29

Huda, I. A. (2020). PERKEMBANGAN TEKNOLOGI INFORMASI DAN KOMUNIKASI (TIK) TERHADAP KUALITAS PEMBELAJARAN DI SEKOLAH DASAR. JURNAL PENDIDIKAN Dan KONSELING, 1(2), 143-149.

Jocom, H., Kameo, D. D., Utami, I., \& Kristijanto, A. I. (2016). Air dan Konflik: Studi Kasus Kabupaten Timor Tengah Selatan. JURNAL ILMU LINGKUNGAN, 14(1), 51-61.

Maukari, A. M., Bunganaen, W., \& Utomo, S. (2016). PERENCANAAN TEKNIS JARINGAN AIR BERSIH DI DESA NUNUSUNU KECAMATAN KUALIN KABUPATEN TIMOR TENGAH SELATAN. Jurnal Teknik Sipil, V(1), 15-28. 
Muttaqin, M. A., Susanto, A., \& Muslih. (2020). APLIKASI STOK AUDIT DI PT. MEDIA SARANA DATA BERBASIS ANDROID DENGAN ARSITEKTUR MODEL VIEW PRESENTER. Jurnal Maklumatika, 6(2), 112-123.

Novita, M. D., \& Marsono, B. D. (2019). Perencanaan Sistem Distribusi Air Minum Kecamatan Arjasa Kabupaten Jember. JURNAL TEKNIK ITS, 8(2), D112-D117.

Prasanti, D., \& Indriani, S. S. (2018). PENGEMBANGAN TEKNOLOGI INFORMASI DAN KOMUNIKASI DALAM SISTEM E-HEALTH ALODOKTER.COM. Jurnal Sosioteknologi, 17(1), 93-103. http://dx.doi.org/10.5614\%2Fsostek.itbj.2018.17.1.9

Prayitno, E., Kurniawati, D., \& Arvianto, I. R. (2018). PEMANFAATAN TEKNOLOGI INFORMASI DAN KOMUNIKASI (TIK) UNTUK MENINGKATKAN KUALITAS PEMBELAJARAN. SEMINAR NASIONAL CALL FOR PAPER \& PENGABDIAN MASYARAKAT, 1(01), 401-414.

Rachman, A., Fatimah, D. A., Nugroho, H., Sulistyowati, \& Widodo, W. (2019). Development of Educational Game Traffic Signs Based on Android for Elementary School Students. 61.

Rachman, A., Prasetyo, B. E., Arief, R., Ferdiansyah, M. A., \& Sulistyowati, S. (2019). Pengembangan Aplikasi Game Pembelajaran Matematika "Momon Math Run" Berbasis Desktop Menggunakan Model Waterfall. Seminar Nasional Sains Dan Teknologi Terapan VII 2019, 433-438.

Rahmawati, R., Ramandani, J. P., Husna, I., Lutfiana, K. N., \& Shabrina, K. L. N. (2018). Keanekaragaman Tumbuhan Lapis Bawah di Umbul Songo Kawasan Taman Nasional Gunung Merbabu. Eksplorasi Keanekaragaman Hayati Sebagai Upaya Konservasi Di Era Disrupsi, 99-104.

Ritonga, P. S. (2011). "AIR" SEBAGAI SARANA PENINGKATAN IMTAQ (INTEGRASI KIMIA DAN AGAMA). Jurnal Sosial Budaya, 8(2), 267-276.

Rohman, H., \& Sheralinda, S. (2020). Pengembangan Sistem Informasi Rawat Jalan dan Pelayanan Persalinan di Klinik Berbasis Web. Jurnal Kesehatan Vokasional, 5(1), 53-66.

Rozi, N. F., Ruswiansari, M., Rachman, A., Wardhana, S. R., \& Istiyanto, L. (2019). The Development of LIDI: A Web-Based Car Rent Marketplace Application in Sidoarjo, Indonesia. The 1st International Conference on Advanced Engineering and Technology, IOP Conf. Series: Materials Science and Engineering 462 (2019) 012052, 1-6. https://doi.org/10.1088/1757-899X/462/1/012052

Saputra, A., \& Sucahyo, Y. G. (2018). Rancangan Tata Kelola Organisasi Sistem Manajemen Keamanan Informasi Dinas Komunikasi dan Informatika Kabupaten Bekasi. Jurnal IPTEKKOM, 20(1), 17-29.

Sulistyowati, Hendrianto, \& Rachman, A. (2017). IMPLEMENTASI ALGORITMA GREEDY STRING TILING PADA PENDETEKSIAN KEMIRIPAN PROGRAM JAVA. Institut Teknologi Adhi Tama Surabaya. http://conference.itats.ac.id/index.php/sntekpan/2017

Sutoyo. (2010). Keanekaragaman Hayati Indonesia Suatu Tinjauan: Masalah dan Pemecahannya. Buana Sains, 10(2), 101-106.

Witanti, W., Dewi, W., \& Umbara, F. R. (2020). SISTEM INFORMASI PERPUSTAKAAN DIGITAL DI UNIVERSITAS JENDERAL ACHMAD YANI. Jurnal IKRA-ITH Informatika, $4(2), 47-54$. 